\title{
INFLUENCE OF INITIAL SURFACE CONDITION ON INTENSITY OF POROUS STRUCTURE FORMATION IN A METALLIC MATERIAL DURING LASER ACTION
}

\author{
S.P. Murzin, E.E. Kostriukov, V.A. Glushchenkov, S.A. Afanasiev, M.V. Blokhin \\ Samara National Research University, Samara, Russia
}

\begin{abstract}
The influence of the initial surface condition on the intensity of porous structure formation in a metallic material during laser action has been determined. Two groups of samples were studied: $\mathrm{Cu}-\mathrm{Zn}$ alloy with and without the oxide layer. Surface morphology of the samples has been researched using electron microscopy. The centre area of laser treatment zone on the surface of the samples is heated up to $\geq 500^{\circ} \mathrm{C}$ not less than $180 \mathrm{~s}$. At that, a porous structure with an irregular distribution of pores on the surface appears. Removing the oxide film by mechanical treatment leads to significant improvement of conditions of pore formation on the surface of the metal samples in the case of laser treatment. Consequently, a structure with a uniform pore distribution appears. After that, the temperature in the centre of the heat-affected zone increases to $500^{\circ} \mathrm{C}$ for $12-20 \mathrm{~s}$. This leads to a significant increase of pore formation intensity. In the case of using the obtained material as a catalyst, an increase of its specific surface area allows for the improvement of conditions for hetero-phase chemical and catalytic reactions, which increases the productivity of the catalytic actions.
\end{abstract}

Keywords: surface, porous structure, formation, metallic material, laser action.

Citation: Murzin SP, Kostriukov EE, Glushchenkov VA, Afanasiev SA, Blokhin MV. Influence of initial surface condition on intensity of porous structure formation in a metallic material during laser action. CEUR Workshop Proceedings, 2016; 1638: 83-88. DOI: 10.18287/1613-0073-2016-1638-83-88

\section{Introduction}

Metallic materials with high specific surface area have a number of unique physical properties that define the main areas of their application in the production of chemical species with the use of catalysts. However, existing methods and technologies of synthesising such metallic materials have significant restrictions and manufactured samples are relatively expensive and have worst mechanical properties. Conditions for the formation of porous structures with a high specific area for metallic material catalysts via laser action have been determined in works [1-3]. Experimental research on defin- 
ing the distinctions between structure formation in solid-crystalline materials, such as a two-component solid solution, have been conducted [4-6]. One of the components is characterized by a higher vapour tension. It has been established that, in case of pulseperiodical radiation, the intensification of pore formation, as well as their shape and dimensions, are conditioned by heating-rate modes. These modes are defined by the value and distribution of power density in a heat-affected zone, duration of treatment, and laser pulse frequency. Investigation of the samples surfaces showed that formation of the pores (both simple and which form branched channels) is more intensive in near-surface layer. It has been defined in printed works [7-10] that the main mechanism of this structure formation is the well-known mechanism of sublimation of an alloy's component with higher vapour tension. Concentration gradient is set up in a material and further this component sublimates with the surface to the extent to which it's diffusion to the surface is provided. In order to provide task-oriented adjustment of power density distribution of acting laser radiation, such elements of diffractive computer optics as radiation focusers are used [11-14]. The aim of this work is to define an influence of initial surface condition on intensity of porous structure formation in metallic materials under laser action.

\section{Results of experimental research}

For conducting research a ROFIN DC $010 \mathrm{CO}_{2}$ slab-laser has been used. Its wavelength is $10.6 \mu \mathrm{m}$, pulse repetition frequency range is $2-5000 \mathrm{~Hz}$, and range of output power is $100-1000 \mathrm{~W}$. Laser radiation has been formed via an optical system based on a diffractive optical element. Laser action has been carried out under the following conditions: laser power was $330 \mathrm{~W}$, pulse repetition frequency was $3 \mathrm{~Hz}$, and diameter of laser spot on the samples' surfaces was $16 \mathrm{~mm}$. In order to measure the surface temperature of the samples, made of $\mathrm{Cu}-\mathrm{Zn}$ alloy brass L62 with a $60.5-63.5 \%$ content of copper, a FLIR SC7300 thermo vision camera has been used. It is capable of measuring temperature in the range of $5-1500^{\circ} \mathrm{C}$. The camera is coupled with $\mathrm{InSb}$ detector with an IR wavelength detection range of 1.5-5.1 $\mu \mathrm{m}$. Samples, with dimensions of $25 \times 35 \mathrm{~mm}$ and thickness of $50 \mu \mathrm{m}$ prepared in two ways have been researched: 1) samples with a thin oxide film and 2) samples that have had the oxide layer removed by mechanical treatment. Morphology of the $\mathrm{Cu}-\mathrm{Zn}$ alloy sample surfaces has been researched by electron microscopy, with the use of a Phillips 525 scanning electron microscope with an accelerating voltage of $25 \mathrm{kV}$. The Phillips 525 scanning electron microscope is intended for topographic and phase analysis of the surfaces of metallic and non-metallic materials and semi-quantitative elemental analysis. Its parameters were set as follows: voltage range for acceleration of the electron beam was $3-30 \mathrm{kV}$; resolution was up to $10 \mathrm{~nm}$; minimum 20 times magnification. In contrast with an optical microscope, a scanning electron microscope has higher depth of focus and it makes research of metal surfaces with relief, as well as porous, structures possible.

The centre area of the laser action zone on the surfaces of samples with a thin oxide film was heated up to $\geq 500^{\circ} \mathrm{C}$ not less than 180 s. Fig. 1 show the temperature-time relationship for the centre point of the sample being processed with the laser. Fig.2 shows the distribution of the temperature along a sample during $185 \mathrm{~s}$. After the sam- 
ple had been processed a porous structure with an irregular distribution of pores appeared on the surface (Fig.3). Thermal-affected zone of the samples with thin oxide film is characterized by areas, where specific surface area is significantly decreased. Removing of oxide film by mechanical treatment allows to improve conditions for the pores formation on the samples surface via laser action. At that, heating of the heataffected zone center up to $500^{\circ} \mathrm{C}$ occurs for $12-20 \mathrm{sec}$ and it leads to significant increase of the pores formation intensity. As a result, porous structure with regular distribution of pores on the surface appears (Fig.4).

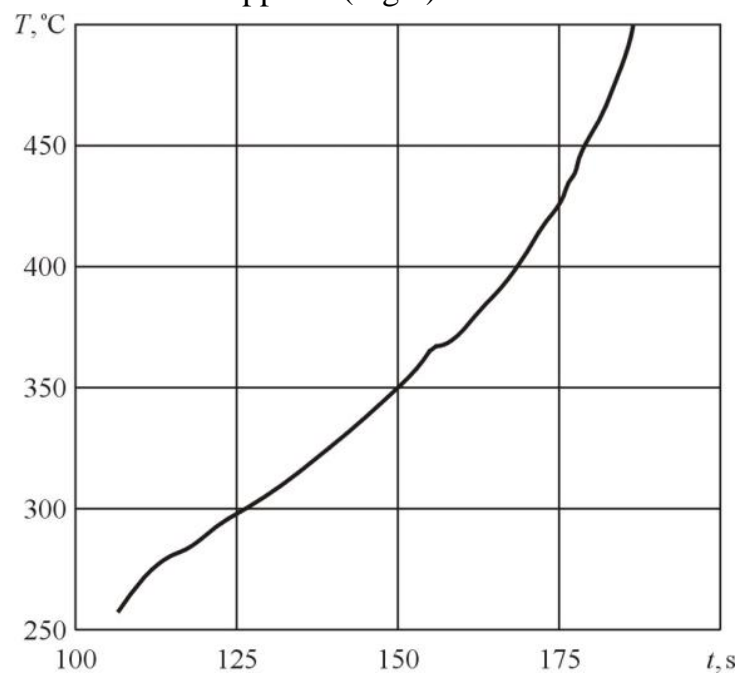

Fig. 1. Temperature-time relationship for the heat affected zone at the centre of the surface of a

$\mathrm{Cu}-\mathrm{Zn}$ sample with a thin oxide film under laser treatment

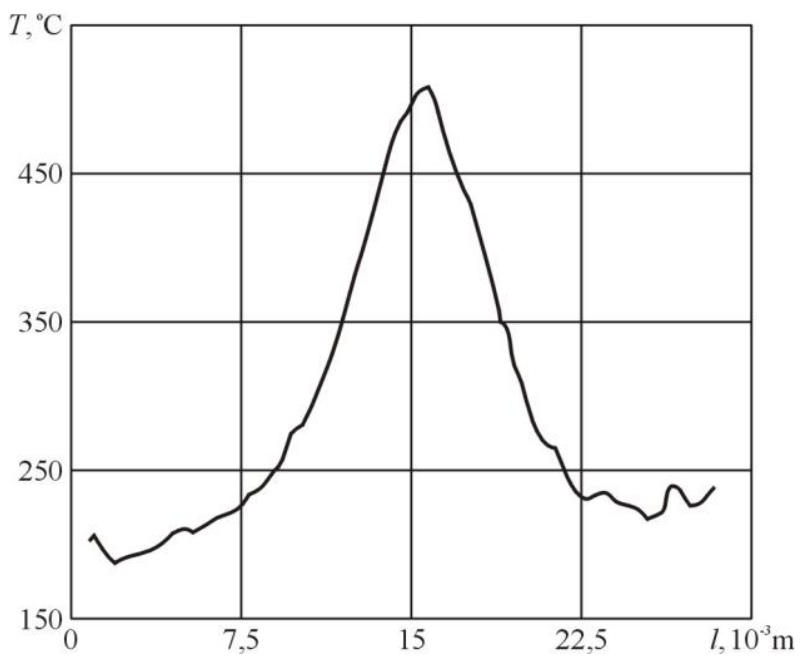

Fig. 2. Distribution of the temperature along the sample with thin oxide film in time of $185 \mathrm{~s}$ 


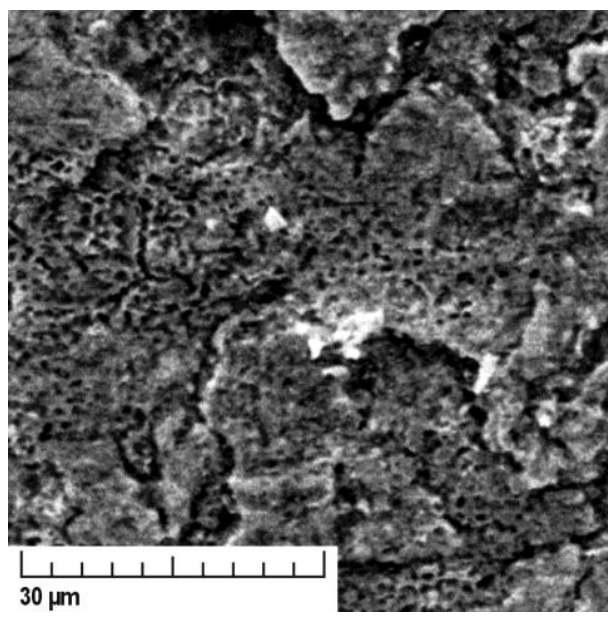

Fig. 3. Morphology of the surface of a sample with a thin oxide film i.e. oxide layer was not removed by mechanical treatment before laser action

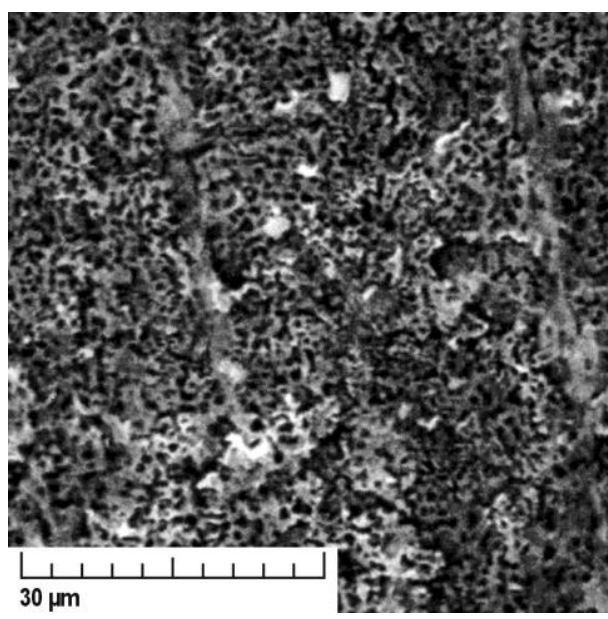

Fig. 4. Morphology of the sample surface after laser action, the oxide film was previously removed by mechanical treatment

The prospects of $\mathrm{Cu}$-based alloys with a high specific surface area for applications such as catalysts are viable. The catalytic properties of $\mathrm{Cu}$ can be used for the synthesis of aldehydes and ketones from primary and secondary alcohols by oxidation and oxidative dehydrogenation methods. Usually, the activity of a catalyst in heterogeneous catalysis is proportional to its specific surface area. For obtained porous materials the surface area, which reacts with chemical reaction reagents, must significantly exceed the surface area of a continuous solid material. At that, specific surface area achieves $10^{3} \mathrm{~m}^{2} / \mathrm{g}$. In the case of nanoporous materials' applications as catalysts, their capabilities of the activity increase is not limited to an increase of specific surface 
area. In this case, atoms on the surface and in the near-surface layer with high surface curvature affect the material properties, as well as the properties of the atoms and molecules adsorbed by pores from the environment.

\section{Conclusion}

Two groups of samples were studied: $\mathrm{Cu}-\mathrm{Zn}$ alloy with and without the oxide layer. Samples with an oxide layer heated to $500^{\circ} \mathrm{C}$ not less than $180 \mathrm{~s}$ showed a significantly decreased rate of pore formation as compared to non-oxide samples. The porous structure of these samples with oxide films are characterized by irregular pores distributions on the surfaces and by presence of areas, where specific surface area is significantly decreased. By removing the oxide film by mechanical treatment leads to a significant improvement of the conditions for pore formation via laser action. Heating the centre of the heat-affected zone to up to $500^{\circ} \mathrm{C}$ occurs for $12-20 \mathrm{~s}$. As a result of this, porous structure with a regular distribution of pores appears on the surface. An increase of their specific surface are allows for the improvement of conditions for heterophase chemical and catalytic reactions, leading to an increase of catalyst efficiency.

\section{References}

1. Murzin SP. Exposure to laser radiation for creation of metal materials nanoporous structures. Opt. Laser Technol., 2013; 48: 509-512.

2. Kazanskiy NL, Murzin SP, Osetrov YeL, Tregub VI. Synthesis of nanoporous structures in metallic materials under laser action. Opt. Laser Eng., 2011; 49(11): 1264-1267. DOI: 10.1016/j.optlaseng.2011.07.001.

3. Murzin SP. The research of intensification's expedients for nanoporous structures formation in metal materials by the selective laser sublimation of alloy's components. Computer Optics, 2011; 35(2): 175-179.

4. Murzin SP, Tregub VI, Melnikov AA, Tregub NV. Application of radiation focusators for creation of nanoporous metal materials with high specific surface area by laser action. Computer Optics, 2013; 37(2): 226-232.

5. Murzin SP. Determination of conditions for the laser-induced intensification of of mass transfer processes in the solid phase of metallic materials. Computer Optics, 2015; 39(3): 392-396. DOI: 10.18287/0134-2452-2015-39-3-392-396.

6. Murzin SP. Formation of nanoporous structures in metallic materials by pulse-periodic laser treatment. Opt. Laser Technol., 2015; 72: 48-52.

7. Murzin SP, Shakhmatov EV, Igolkin AA, Musaakhunova LF. A study of vibration characteristics and determination of the conditions of nanopores formation in metallic materials during laser action. Procedia Engineering, 2015; 106: 266-271.

8. Murzin SP, Kryuchkov AN. Influence of conditions of the samples fixation on the intensity of the nanoporous structure formation in the metallic material by laser action with thermocycling. Procedia Engineering, 2015; 106: 272-276.

9. Murzin SP. Synthesis of metal materials nanoporous structures with cyclic elasto-plastic deformation under laser treatment using radiation focusators. Computer Optics, 2014; 38(2): 249-255. 
10. Murzin SP. Method of composite nanomaterials synthesis under metal/oxide pulseperiodic laser treatment. Computer Optics, 2014; 38(3): 469-475.

11. Golovashkin DL, Kasanskiy NL. Solving diffractive optics problems using graphics processing units. Optical Memory and Neural Networks (Information Optics), 2011; 20(2): 85-89. DOI: 10.3103/S1060992X11020019.

12. Kazanskiy NL. Research \& education center of diffractive optics. Proceedings of SPIE The International Society for Optical Engineering, 2012; 8410(84100R). DOI: $10.1117 / 12.923233$.

13. Kazanskiy NL, Kotlyar VV, Soifer VA. Computer-aided design of diffractive optical elements. Optical Engineering, 1994; 33(10): 3156-3166. DOI:10.1117/12.178898.

14. Doskolovich LL, Kazanskiy NL, Soifer VA. Comparative analysis of different focusators focusing into a segment. Optics and Laser Technology, 1995; 27(4): 207-213. DOI: 10.1016/0030-3992(95)93746-E.

15. Mihajlovskij, Ju.N. Atmosfernaya korroziya metallov i metody ikh zashchity. Moscow: Metallurgiya, 1989. 101 p.[in Russian] 